\title{
APORTES PARA A IMPLANTAÇÃO DE REPOSITÓRIO DE NARRATIVAS NA UFPA: disseminando e ampliando o acesso à informação
}

\author{
Erik André de Nazaré Pires \\ Bibliotecário-Documentalista na \\ Universidade Federal do Pará. \\ Especialista em Ciência da Informação \\ pelo Centro de Pós-graduação da \\ Faculdade Integrada Carajás. \\ E-mail: eriknazare@hotmail.com

\section{Jetur Lima de Castro \\ Pesquisador no Grupo de pesquisa Digital na Rede Brasileira de Preservação Digital do Instituto Brasileiro de Informação em Ciência e Tecnologia. Bacharel em Biblioteconomia pela Universidade Federal do Pará. \\ E-mail: jetur.er@gmail.com} \\ sobre Estudo e Práticas de Preservação
}

\section{Alessandra Nunes de Oliveira}

Bacharel em Biblioteconomia pela Universidade Federal do Pará. E-mail:

alessandranunesoliveira@gmail.com

\section{RESUMO}

Ao avaliar a necessidade do desenvolvimento institucional e o acesso ao conhecimento científico que compõe o Sistema de Bibliotecas da Universidade Federal do Pará (SIBI-UFPA), a partir de atividades profissionais que qualificam e capacitam os usuários por meio de oferta de produtos e serviços, objetiva-se discutir uma proposta para a implantação de um repositório de narrativas na Universidade Federal do Pará. Trata-se de uma pesquisa exploratória de base bibliográfica, tendo como premissa tornar o conhecimento mais explícito por meio da ampliação do Repositório Institucional da Universidade Federal do Pará (RIUFPA). Apresenta-se a sugestão da produção de um repositório de narrativas que, no futuro, poderá armazenar vídeos e imagens, diferentemente do RIUFPA atual que tão-somente armazena texto completo. Por fim, a partir da elaboração do repositório poderá trazer o efeito esperado para a comunidade científica e para os profissionais bibliotecários, uma vez que poderão valer-se dessa tecnologia para ampliar o melhoramento na gestão informacional no SIBI-UFPA.

Palavras-Chave: Informação. Disseminação. Acesso aberto. Repositório. Sistema de Bibliotecas.

\section{CONTRIBUTIONS TO THE IMPLEMENTATION OF A NARRATIVE REPOSITORY AT UFPA: disseminating and expanding access to information}

\begin{abstract}
It assesses the need of the institutional development and access to the scientific knowledge that it composes the System of Libraries of the Federal University of Pará (SIBIUFPA), starting from professional activities that qualify and they qualify the users, through offer of products and services. It is aimed at to discuss a proposal for the implantation of a repository of narratives in the Federal University of Pará. It is an exploratory research of bibliographical base, tends as premise, to turn the most explicit knowledge starting from the enlargement of the Institutional Repository of the Federal University of Pará (RIUFPA). He/she comes the suggestion of the production
\end{abstract}


of a repository of narratives that can store videos in the future, images, deferentemente of current RIUFPA that only stores text videos, images, deferently of the current RIUFPA that only stores full text. Finally, from the elaboration of the repository can bring the expected effect to the scientific community and to the librarians, since they will be able to use this technology to increase the improvement in information management in the (SIBIUFPA).

Keywords: Information. Dissemination. Open access. Repository. Libraries System.

\section{INTRODUÇÃO}

Diante das novas tecnologias da comunicação e informação (TIC) a sociedade está intensamente ligada aos mecanismos de acesso à informação de forma livre. 0 cenário em que a humanidade vive tem uma tendência maior em relação à produção de documentos e informações digitais com toda essa gama de conhecimento.

Desse modo, em face de um mundo cada vez mais globalizado, aumentam-se substancialmente os canais e as formas de divulgação dos registros do conhecimento humano. Sobre isso, a temática em questão é pertinente, no sentido de discutir uma proposta para a implantação de um repositório de narrativas na Universidade Federal do Pará.

A SIBI-UFPA atualmente conta com aproximadamente cem (100) bibliotecários no seu corpo técnico; é um dos cargos com mais servidores no quadro da UFPA, por se tratar de um profissional que tem a missão precípua de organizar, tratar e disseminar a informação. Esse profissional trabalha com atividades principais ligadas à gestão e à disseminação da informação, seja em suporte impresso ou digital, visando atender os mais diversos tipos de usuários.

Assim sendo, o estudo em questão vem a reboque da pesquisa na Universidade Federal do Pará, mais precisamente nas bibliotecas que compõem o Sistema de Bibliotecas da UFPA (SIBI-UFPA). Constituem, dessa forma, locais nos quais os bibliotecários exercem suas atividades profissionais visando a qualificação e a capacitação dos usuários, seja por meio de oferta de serviços e produtos, cursos, treinamentos, minicursos, dentre outras atividades inerentes ao atendimento informacional dos usuários de forma perspicaz. 
Por conseguinte, apresenta a sugestão da produção de um repositório de narrativas que, no futuro, poderá armazenar vídeos e imagens, diferentemente do RIUFPA atual que tão-somente armazena texto completo (dissertações, teses e artigos). Por fim, a partir da elaboração do repositório de narrativas, poderá surtir o efeito esperado para a comunidade acadêmica e para os profissionais bibliotecários, uma vez que poderão valerse dessa tecnologia para ampliar o melhoramento na gestão informacional no SIBI-UFPA.

\section{REVISÃO DE LITERATURA}

A revisão bibliográfica em questão é de cunho conceitual, por apresentar definições da literatura a respeito de repositórios, narrativas e também sobre gestão do conhecimento, alvos principais da proposição da pesquisa em foco. Dessa maneira, foi escolhida essa abordagem pelo fato da pesquisa propor um novo enfoque em termos de desenvolvimento de repositório, o qual vem gerar um produto inovador para a UFPA.

As TIC's, dentre suas inúmeras funções, são utilizadas para alicerçar o desenvolvimento de novas tecnologias, nas quais a informação possa ser tratada, organizada e recuperada pelos usuários. Notoriamente, a Informação Científica Tecnológica ${ }^{1}$ converte-se em um modelo catalisador por meio da transferência de informações que é subsidiada aos modelos técnicos de precisão lógica para representar e recuperar em sistemas de informação.

A recuperação deve ocorrer de forma condizente ao que se está pesquisando, e nessa miscelânea de tecnologias que são desenvolvidas a todo o momento surge o repositório, o qual se configura como uma ferramenta tecnológica que tem no seu escopo o objetivo de preservar a coleção digital (MARCONDES; SAYÃO, 2009), ou seja, é uma tecnologia que, além do acesso livre, serve também de preservação informacional, independente da tipologia que se queira armazenar.

No que tange ao segmento científico, as contribuições para a sociedade acadêmica no desenvolvimento do repositório acontecem pelo fato dessa tecnologia estar sendo utilizada amplamente pelas universidades e demais instituições de ensino do Brasil e do

\footnotetext{
1 [...] insumo básico para o desenvolvimento científico e tecnológico de um país. Esse tipo de informação, resultado das pesquisas científicas, é divulgado à comunidade por meio de revistas. Os procedimentos para a publicação dessa informação foram estabelecidos pelo sistema de comunicação científica, o qual vem se consolidando ao longo de mais de três séculos (KUMAROTO, 2006, p. 91).
} 
mundo. Visando atender às diretrizes do Open Access $^{2}$, consequentemente o que está sendo produzido pelos pesquisadores está sendo disponível gratuitamente a quem tiver interesse de saber quais as novidades em termos de pesquisas científicas (KURAMOTO, 2009).

Um fator preponderante na construção da tecnologia em questão é o fato desse suporte ser uma tecnologia inovadora, diferenciando-se do que é armazenado nos repositórios, os quais normalmente armazenam documentos como teses, dissertações, artigos, dentre outros tipos de documentos produzidos pelos sujeitos que estão ligados à instituição, no caso da universidade: professor, técnico-administrativo e discente da pósgraduação.

A proposição desse tipo específico de repositório concerne à armazenagem e preservação de arquivos no estilo podcast ${ }^{3}$. Esse tipo de formato de armazenamento de informação também pode ser encontrado para se referir à série de episódios de algum programa quanto à forma em que este é distribuído. Consequentemente, o desenvolvimento dessa tecnologia pode vir a ser modelo para que outras instituições de ensino possam desenvolver nessa mesma perspectiva.

Passando para o contexto das narrativas, Brusamolin e Suaiden (2014, p. 29) asseveram que "são relatos orais ou escritos de um ou mais eventos, verdadeiros ou fictícios. A diferença entre uma narrativa e a mera citação de um exemplo está na adição de conteúdo emocional e detalhes sensoriais". Uma narrativa compreende detalhes que serão descritos de acordo com o tema em voga, podendo ser representada pelo diagrama a seguir.

\footnotetext{
${ }^{2}$ Acesso Livre (ou "Acesso Aberto") significa a disponibilização livre na Internet de cópias gratuitas, online, de artigos de revistas científicas revistos por pares (peer-reviewed), comunicações em conferências, bem como relatórios técnicos, teses e documentos de trabalho.

3 É o nome dado ao arquivo de áudio digital frequentemente em formato MP3 ou AAC (este último pode conter imagens estáticas e links), publicado através de podcasting na internet e atualizado via RSS. Também pode se referir à série de episódios de algum programa quanto à forma em que este é distribuído.
} 
Figura 1 - 0 triângulo da narrativa

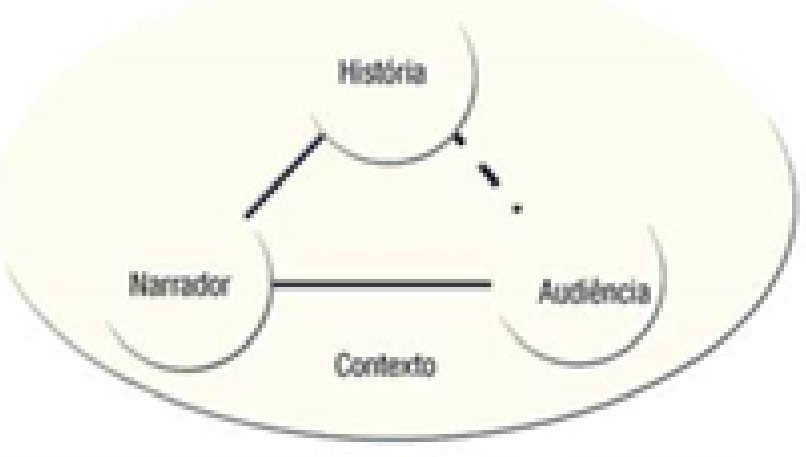

Fonte - Lipman (1999 apud BRUSAMOLIN; SUAIDEN, 2014)

Pode-se perceber que as narrativas compreendem fatos que podem ser não completamente previsíveis, ou seja, dependendo do assunto tratado, o caminho percorrido pode ser diferente do que se possa imaginar.

No âmbito das organizações, o uso de narrativas ocorre em várias culturas e em diferentes países (SWAP et al, 2001) de acordo com o propósito que se pretender atingir, pois uma narrativa é uma poderosa técnica de convencimento e persuasão, já que, por meio dela, pode-se ter conhecimento sobre determinado assunto que o usuário queira saber para sanar uma necessidade informacional.

Echeverria (2004) apresenta uma interessante explanação para o fenômeno da crescente importância conferida à comunicação oral no ambiente organizacional, pois por meio das narrativas é possível ter um recurso estratégico efetivo pelos gestores, os quais percebem que a relação entre narrativas e compartilhar conhecimento são de suma importância para o engrandecimento organizacional. Segundo Terra (2002), se os gestores aprenderem a tornar suas narrativas mais eficazes, isto é, aprimorá-las, poderão utilizá-las em seu potencial máximo.

Assim sendo, a partir de estratégias que identificam as necessidades informacionais, nos quais abrangem os fluxos formais e informais da informação que desembocam nas atividades cotidianas e na tomada de decisão do ambiente organizacional, formando no seu cerne "a constelação do agir e do falar modifica-se [...], transformando-se num simples meio de informação" (HABERMAS, 1990, p. 76).

Com efeito, as agregações das tecnologias no ambiente informacional vêm para suprir necessidades frentes aos usuários e até mesmo dos profissionais da informação na utilização de ferramentas para melhorar a dinâmica das comunicações a partir da gestão 
do conhecimento. Para Choo (2003), novos conhecimentos permitem à organização desenvolver novas capacidades e melhorar os processos organizacionais.

Atualmente, a gestão do conhecimento está preocupada com o desenvolvimento do ambiente organizacional por meio do compartilhamento de conhecimentos e de valores. Nonaka e Takeuchi (1997) definem um paradigma de gestão do conhecimento, classificando em dois modelos: tácito e explícito.

O conhecimento tácito diz respeito ao que está enraizado nas experiências de um sujeito, bem como é altamente pessoal, possui uma importante dimensão de esquemas, modelos mentais, crenças e percepções que refletem o modo como se vê a realidade. Esse tipo de conhecimento é o alvo no estudo em questão, pois objetiva transformar esse conhecimento de forma que seja acessado de maneira eficiente e perspicaz.

Conforme Choo (2003), as organizações do conhecimento, como as bibliotecas universitárias, devem estar abertas ao diálogo para desenvolver ferramentas que colaborem com suas atividades acadêmicas, no sentido de poder reorganizar os processos das ações das técnicas, da organização, da recuperação e da disseminação nos espaços organizacionais nos quais emergem a informação, de modo que seja capaz de pensar num entendimento interdisciplinar, bem como em habilidades e competências comunicativas.

Já o conhecimento explícito é aquele formalizado e expresso por meio de documentação registrada tais como livros, artigos de periódicos, teses, dissertações e demais documentos, sendo que a proposta da pesquisa é transformar o conhecimento tácito em explícito, processo conhecido como externalização, partindo da configuração de que narrar é um processo de socialização de conhecimento tácito que desenvolve um campo de interação e atua como um facilitador do compartilhamento (NONAKA; TAKEUCHI, 1997).

A construção do conhecimento é conseguida quando se reconhece o relacionamento sinérgico entre o conhecimento tácito e o conhecimento explícito dentro de uma organização, e quando são elaborados processos sociais capazes de criar novos conhecimentos por meio da conversão do conhecimento tácito em conhecimento explícito [...] As organizações precisam aprender a converter o conhecimento tácito, pessoal, em conhecimento explícito, capaz de promover a inovação e o desenvolvimento de novos produtos. Enquanto as organizações ocidentais tendem a se concentrar no conhecimento explícito, as empresas japonesas fazem a diferenciação entre o conhecimento tácito e explícito e reconhecem que o conhecimento tácito é uma fonte de vantagem competitiva. (CHOO, 2003, p.37). 
Assim, estando imerso no fluxo de informação, o ambiente organizacional poderá compartilhar de modo ativo, direto e não mediado da captação da informação. Logo, os usuários poderão obter as informações de modo diferente na busca e na apreensão da informação a partir da aplicação do repositório de narrativas.

Por conseguinte, a literatura traz um arcabouço teórico condizente, permitindo que o transcurso da pesquisa científica seja realizado com qualidade e presteza, dentro dos ditames que a ciência apregoa, ou seja, com forte e consolidado embasamento teórico.

\section{PROCEDIMENTOS METODOLÓGICOS}

O procedimento metodológico e operacional da pesquisa científica deve ser norteado por metodologia que seja adequada com a proposição de estudo, haja vista que o percurso metodológico correto é essencial para a construção de um novo conhecimento.

A partir dessa perspectiva, o estudo consiste em uma abordagem exploratória devido a "ter o objetivo de reunir dados, informações, padrões, ideias ou hipóteses sobre um problema ou questão de pesquisa com pouco ou nenhum estudo anterior" (BRAGA, 2007, p. 25). Sua premissa é gerar um produto que terá como pressuposto o acesso à informação contida no conhecimento tácito de cada profissional pesquisado.

Logo, possui como alicerce a pesquisa bibliográfica, pois é tida como fase essencial e basilar do transcurso científico (MARCONI; LAKATOS, 2010). Seguindo essa linha, de acordo com Faria, Cunha e Felipe (2011, p. 32), esse tipo de pesquisa visa "o desenvolvimento de um trabalho cujo problema exija abordagem teórica [...] caracterizando como uma técnica de aprofundamento teórico em busca de soluções de problemas previamente definidos" em virtude da sua caracterização que é provocar a análise e a reflexão sobre a temática abordada.

Dessa forma, faz-se necessário explicitar que este estudo é uma proposta, e, portanto, ainda será operalizado, o que almejará o melhoramento na gestão informacional no SIBI-UFPA. Assim sendo, envolverá a abordagem quantitativa que buscará “[...] quantificar opiniões, dados, nas formas de coleta de informações, assim como também com o emprego de recursos e técnicas estatísticas [...]" (OLIVEIRA, 2001, p. 115), e qualitativa, porquanto “[...] preocupa-se em analisar e interpretar aspectos mais profundos, descrevendo o comportamento humano. 0 que fornecerá uma análise mais 
detalhada sobre as investigações, hábitos, atitudes, tendências de comportamento etc" (MARCONI; LAKATOS, 2009, p. 48).

Além disso, utilizar-se-ão entrevistas com o público alvo, já que esse tipo de metodologia tem no seu cerne a comunicação imediata entre duas ou mais pessoas, abarcando uma comunicação imediata entre o entrevistado e o entrevistador. As entrevistas serão gravadas por meio de aparelho celular ou outra ferramenta disponível que seja adequada para realizar tal procedimento. A partir do recolhimento dos dados, será feito um estudo, seguindo os moldes do princípio da categorização de Bardin (1977) que, enquanto método de organização e análise dos dados, possui como principal característica aceitar que o seu foco seja qualificar as vivências do sujeito, bem como suas percepções sobre determinado objeto e seus fenômenos, sendo, portanto, uma maneira de interpretar de forma adequada o que cada sujeito irá desenvolver durante a entrevista (BARDIN, 1977).

Realizado o levantamento e codificação dos dados, será realizado a conversão das informações extraídas das entrevistas, que serão transformado em formato de áudio para que seja incluso no repositório, serão preenchido os metadados ${ }^{4}$ concernentes aos podcasts em questão, para que seja feita Representação Descritiva e Temática das Informação e por fim será disponibilizado para o acesso do interagente sem qualquer tipo de restrição.

\section{REPOSITÓRIO DE NARRATIVAS: VISANDO O ACESSO À INFORMAÇÃO}

A UFPA compõe o Sistema de Bibliotecas (SIBI-UFPA), capazes de proporcionar qualificação e capacitação para: discentes, docentes, técnico-administrativos e comunidade em geral, tendo em vista formar profissionais altamente qualificados, visando o desenvolvimento de novos conhecimentos e de novas maneiras de resolver os problemas enfrentados pela população. Têm-se como exemplos de benefícios gerados para a população mais precisamente projetos de extensão: construção de eco barco, desenvolvimento de robô capaz de fazer uma cirurgia, enfim, a UFPA tem uma multidisciplinaridade de profissionais aptos a contribuírem para a sociedade da melhor maneira possível.

\footnotetext{
${ }^{4}$ São marcos ou pontos de referência que permitem circunscrever a informação sob todas as formas, pode se dizer resumos de informações sobre a forma ou conteúdo de uma fonte.
} 
Assim sendo, a UFPA conta atualmente com o Repositório Institucional (RIUFPA), que armazena as teses e dissertações e artigos de pesquisadores e servidores da UFPA, formando várias coleções digitais com a missão de armazenar, preservar, organizar e disseminar amplamente o acesso à informação, sendo administrado atualmente pelos bibliotecários Diego Bil Silva Barros (Coordenador do Setor de Gestão de Recursos Informacionais) e Cleide Furtado Nascimento Dantas (Coordenadora do Setor de Edição de Produtos Informacionais).

Partindo desse contexto, o estudo em voga propõe a elaboração de um Repositório Digital (voltado para narrativas) que, segundo Dodebei (2009), é um ferramental tecnológico que serve como base de dados digital e virtual (web-bases database), de caráter coletivo e cumulativo (memória da instituição), de acesso aberto e interoperável que coleta, armazena, dissemina e preserva digitalmente a produção intelectual da instituição, sendo que, no que concerne ao desenvolvimento do referido repositório de narrativas, serão utilizados critérios e categorias destacadas a seguir.

Assim, contextualiza-se o fazer do profissional bibliotecário, uma vez que este é apto a trabalhar com tecnologias que possam vir a colaborar com os ditames da pesquisa científica; e o repositório em voga poderá ser uma ferramenta amplamente utilizada pela comunidade acadêmica. Além de que, a partir dessa tecnologia, podem ser desenvolvidos outros tipos de repositórios voltados aos pesquisadores e profissionais que estão ligados à UFPA.

Desse modo, a partir da elucidação da proposta do repositório (voltado para narrativas), esperar-se-á: a elaboração do repositório com o efeito esperado para a comunidade científica; a expansão do conhecimento tácito com alto índice de utilização, e, por fim, a ampliação do uso dessa tecnologia para o melhoramento na gestão informacional das bibliotecas que compõem o SIBI-UFPA.

Observa-se que o bibliotecário é um dos profissionais mais aptos a gerenciar o insumo mais importante do século XXI, a informação, sobretudo no que diz respeito ao gerenciamento informacional. Seguindo esse cenário, a UFPA tem uma das suas vertentes voltadas para a construção do conhecimento em que a sociedade irá se beneficiar do que está sendo produzido, visando sempre proporcionar retorno para a comunidade, sendo que é indissociável o ensino, a pesquisa e a extensão.

Partindo desse contexto, situa-se que a relação social possa estar voltada no sentido de como o bibliotecário pode atuar na gestão da informação e do conhecimento, 
de modo que o acesso a esse gerenciamento será disponível de maneira global, com acesso irrestrito e sem barreiras, visto que o repositório tem este viés: ser uma ferramenta de busca e acesso informacional de maneira livre, caracterizando no seu intuito o paradigma do Open Access.

Diante dessa constante e ininterrupta construção de conhecimentos, verifica-se que o bibliotecário precisa estar qualificado para auxiliar nos desenvolvimentos de tais conhecimentos por meio de uma proficiente e dinâmica gestão dos materiais informacionais, pois estão sob sua responsabilidade de levar ao usuário o acesso facilitado à informação, seja no desenvolvimento de serviços e produtos aos seus usuários, seja na criação de ferramentas que irão potencializar as pesquisas, como por exemplo: desenvolver aplicativos concernentes à recuperação fácil e ágil da informação. Enfim, o bibliotecário deve estar sempre preparado para atender as demandas que podem surgir.

No tocante aos critérios na escolha do público que irá pertencer ao repositório, serão levados em consideração os atores que estão vinculados à UFPA: docentes e técnicoadministrativos, constituindo, dessa forma, uma comunidade considerável de sujeitos aptos a colaborarem com o povoamento do repositório.

As categorias que estão alinhadas na referida proposta são os mais variados profissionais que atuam na UFPA: bibliotecários, administradores, engenheiros, assistentes sociais e demais profissionais que serão escolhidos de acordo com a posição hierárquica que exercem, como por exemplo, gestores de unidades: a diretora da Biblioteca do Campus de Tucuruí, o Engenheiro Civil do Campus Universitário de Ananindeua, fazendo, assim, uma triagem consistente, já que a UFPA conta com uma quantidade enorme de servidores; além de contar com a participação de docentes exercendo cargo de diretorias das faculdades que põem a UFPA.

As narrativas que serão aceitas dizem respeito a experiências dos profissionais e docentes no tocante ao conhecimento obtido durante o tempo que estão trabalhando na UFPA, sob o viés da gestão e conhecimentos teóricos e práticos que foram obtidos durante os anos atuando como servidores na referida Instituição de Ensino Superior (IES). O conteúdo que fará parte do repositório refere-se ao contexto que o servidor da UFPA está inserido, ou seja, no ambiente acadêmico e administrativo, duas vertentes que se fazem presente de maneira constante na universidade. 
Para o desenvolvimento do repositório será utilizado o software Dspace ${ }^{5}$, o mesmo utilizado no RIUFPA, Biblioteca Digital de Monografias da UFPA e no Portal do Livro Aberto da UFPA. Dessa maneira, é mantido um padrão na escolha da plataforma em que será elaborado o novo repositório, e proporcionará aos interagentes mais um produto do SIBI-UFPA.

Vale ressaltar que a pesquisa está na fase de proposta, ou seja, será levada formalmente às coordenações de Gestão de Recursos Informacionais e Edição de Produtos Informacionais da Biblioteca Central, assim sendo a proposta será melhorada para ser efetivamente desenvolvida.

\section{CONSIDERAÇÕES FINAIS}

Este trabalho teve como objetivo propor a implantação de um repositório de narrativas na Universidade Federal do Pará. Assim sendo, como proposta, este estudo está em andamento nas suas constituições, uma vez que os profissionais bibliotecários podem colaborar no sentido de contar suas experiências em termos de gestão nas unidades informacionais que compõem o SIBI-UFPA para a implantação do repositório de narrativas.

Acredita-se que a realização deste trabalho trouxe contribuições significativas quanto à disponibilização e conhecimento do objetivo proposto, visto que sua finalidade é aprimorar a operacionalização do repositório, colocando-o de maneira mais acessível ao público.

Assim, verifica-se que o próximo passo a ser dado estará relacionado à aprovação deste plano e sua operacionalização junto à capacitação dos profissionais bibliotecários da UFPA, sobretudo da Biblioteca Central, que estão atuando para deixar o RIUFPA sempre acessível à comunidade cientifica.

Por fim, os esforços deste plano devem valer de forma atenuante para a questão do repositório de narrativas, o que fornece, portanto, uma preocupação para que a informação torne-se institucionalizada, acessível e que possa agregar valor perante a

\footnotetext{
${ }^{5}$ Software de código fonte aberto que fornece facilidades para o gerenciamento de acervo digital, utilizado para implementação de repositórios institucionais. Suporta uma grande variedade de tipo de documentos, tais como: livros, teses e dissertações, fotografias, filmes, áudio, e outros. Os documentos são organizados em comunidades e coleções. O DSpace é disponibilizado livremente às instituições de investigação, sob a forma de um produto de código aberto, que pode ser livremente adaptado e expandido funcionalmente, nos termos da Licensa BSD Open source license (IBICT, 2012, não paginado).
} 
comunidade científica, professores, funcionários e alunos da universidade. Ver-se-á como essa tecnologia irá colaborar no acesso à informação, apresentando como acontece a gestão do conhecimento no contexto do serviço público, mais precisamente entre os bibliotecários que compõe o SIBI-UFPA, a partir da implantação deste repositório de narrativas.

\section{REFERÊNCIAS}

BARDIN, Laurence. Análise de conteúdo. Lisboa: Edições 70, 1977.

BRAGA, João Alberto de Oliveira. Aspectos relevantes para a seleção de metodologia adequada à pesquisa social em Ciência da Informação. In: MUELLER, Suzana Pinheiro Machado. Métodos para a pesquisa em Ciência da Informação. Brasília, DF: Thesaurus, 2007. p. 17-38.

BRUSAMOLIN, Valério; SUAIDEN, Emir José. Aprendizagem organizacional: o impacto das narrativas. Curitiba: Appris, 2014.

CHOO, C. W. A organização do conhecimento: como as organizações usam a informação para criar significado, construir conhecimento e tomar decisões. São Paulo: Senac, 2003.

DODEBEI, Vera. Repositórios institucionais: por uma memória criativa no ciberespaço. In: SAYÃO, Luis Henrique et al. (Org.). Implantação e gestão de repositórios institucionais: políticas, memória, livre acesso e preservação. Salvador: Edufba, 2009.

ECHEVERRIA, R. Reflexão, diálogo e ética nas organizações. São Paulo: Atlas, 2004.

FARIA, Ana Cristina de; CUNHA, Ivan da; FELIPE, Yone Xavier. Manual prático para

elaboração de monografias: trabalhos de conclusão de curso, dissertações e teses. 5. ed. Petropólis, RJ: Vozes; São Paulo: Universidade São Judas Tadeu, 2011.

HABERMAS, Jurguen. Pensamento Pós-metafísico. Tradução de: Flávio Beno Siebeneichler. Rio de Janeiro: Tempo Brasileiro, 1990.

INSTITUTO BRASILEIRO DE INFORMAÇÃO EM CIÊNCIA E TECNOLOGIA. Sobre o Dspace. Brasília, DF, 2012. Disponível em: <www.ibict.br/dspace>. Acesso em: 15 ago. 2017.

KURAMOTO, Hélio. Repositórios institucionais: políticas e mandatos. In: SAYÃO, Luis et al. (Org). Implantação e gestão de repositórios institucionais: políticas, memória, livre acesso e preservação. Salvador: Edufba, 2009. p. 203-218.

Scholarly information: purpose of a new model for the Brazil. Ciência da Informação, Brasília, DF, v. 35, n. 2, p. 91-102, 2006.

MARCONI, Marina de Andrade; LAKATOS, Eva Maria. Fundamentos de metodologia científica. 7. ed. São Paulo: Atlas, 2010.

Metodologia do trabalho científico: procedimentos básicos, pesquisa bibliográfica, projetos e relatório, publicações e trabalhos científicos. 7. ed. São Paulo: Atlas, 2013. 
Metodologia científica. 6. ed. São Paulo: Atlas, 2011.

MANZINI, E.J. Considerações sobre a elaboração de roteiro para entrevista semi-estruturada. In: MARQUEZINE: M. C.; ALMEIDA, M. A.; OMOTE; S. (Org.) Colóquios sobre pesquisa em Educação Especial. Londrina: Eduel, 2003. p. 11-25.

MARCONDES, Carlos Henrique; SAYÃO, Luis Fernando. Softwares livres para repositórios institucionais: alguns subsídios para a seleção. In: SAYÃO, Luis Henrique et al. (Org.).

Implantação e gestão de repositórios institucionais: políticas, memória, livre acesso e preservação. Salvador: Edufba, 2009.

NONAKA, I; TAKEUCHI, H. Criação de conhecimento na empresa. São Paulo: Campus 1997.

OLIVEIRA, S. L. de. Tratado de Metodologia Científica: Projetos de Pesquisas, TGI, TCC, Monografias, Dissertações e Teses. São Paulo: Pioneira, 2001.

SWAP, W. et al. Using mentoring and storytelling to transfer knowledge in the workplace. Journal of Management Information Science, New York, v. 19, n. 1, 2001.

TERRA, J. C.C. Gestão do conhecimento: o grande desafio empresarial. 2. ed. São Paulo: Negócio Editora, 2001.

UNIVERSIDADE FEDERAL DO PARÁ. Biblioteca Central. Sistema de Bibliotecas. Belém, 2015. Disponível em: <http://bc.ufpa.br/site/index.php/component/content/article/3-paginasestaticas/156-sibi>. Acesso em: 27 maio 2016.

Recebido em: 02 de janeiro de 2017 Aceito em: 23 de agosto de 2017 